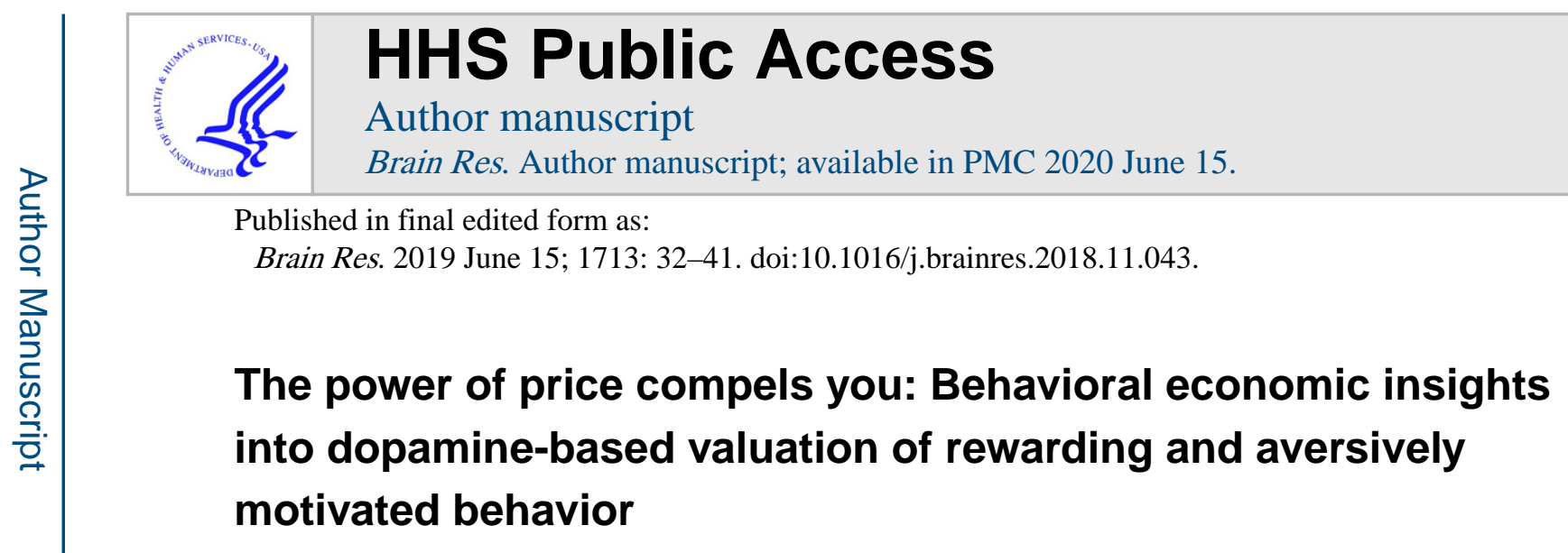

Erik B. Oleson ${ }^{*}$, Jonté B. Roberts

Psychology Department, University of Colorado Denver, United States

\begin{abstract}
The mesocorticolimbic dopamine pathway is generally considered to be a reward pathway. While shortsighted, there is a strong basis for this view of dopamine function. Here, we first describe the role of phasic dopamine release events in reward seeking. We then explain why these release events are being reconsidered as value signals and how we applied behavioral economics to confirm they play a causal role in the valuation of reward. Just because dopamine release can function as a dopamine reward value signal however, does not imply that dopamine is solely a reward molecule. Rather, mesocorticolimbic dopamine appears to mediate many adaptive behaviors, including: reward seeking, avoidance, escape and fear-associated conditioned freezing. While more studies are needed before a consensus is reached on when, where and how dopamine mediates aversively-motivated behavior, its involvement is almost irrefutable. Thus, we next describe the role dopamine plays in these ethologically-relevant defensive behaviors. We conclude by describing our recent behavioral economics results that reveal a causal role for dopamine in the valuation of avoidance.
\end{abstract}

\title{
Keywords
}

Dopamine; Avoidance; Defensive; Escape; Aversion; Behavioral economics

\section{Brief introduction to the mesocorticolimbic dopamine system}

It is becoming increasingly evident that dopamine systems interact within complex neural networks to mediate not only appetitively, but also aversively motivated behaviors. A growing body of evidence supports a role for nigrostriatal dopamine in defensive behaviors, such as fear-induced conditioned freezing (Bouchet et al., 2018; Mika et al., 2015). And, recent evidence suggests dopamine release events arising from non-canonical dopamine populations in the periaqueductal gray and in the dorsal raphe interact with the amygdala to influence behavioral responses to fear (Groessl et al., 2018).

\footnotetext{
*Corresponding author at: CB 173, PO Box 173364, Denver, CO 80217, United States. erik.oleson@ucdenver.edux (E.B. Oleson). Conflict of interest

None.
} 
In the current review we will restrict our discussion to the mesocorticolimbic dopamine system, a neural pathway that is highly conserved across vertebrate species (Smeets et al., 2000). This pathway originates from the ventral tegmental area (VTA) and projects to various neural substrates throughout the brain, including the frontal cortex, amygdala, olfactory tubercle and-most prominently, the nucleus accumbens (NAc) (Swanson, 1982). While dopamine released into various terminal fields influences motivated behavior, we are focusing on the NAc because of its predominance not only in mesolimbic neuroanatomy, but also in the historic motivational literature. The NAc is often described as a limbic-motor (Mogenson et al., 1980) or a Pavlovian-instrumental (Cardinal et al., 2002) interface because it theoretically integrates emotional information with learned associations to guide advantageous behavior. While dopamine neurons predominate in the VTA $(\sim 60 \%)$, it is important to note that GABA and glutamate neurons are also prevalent and capably modulate dopamine neural activity (Margolis et al., 2012; Morales and Margolis, 2017; Nair-Roberts et al., 2008; Swanson, 1982; Tagliaferro and Morales, 2008; Yamaguchi et al., 2007). Secondary messengers within the VTA (e.g., NO, $\mathrm{H}_{2} \mathrm{O}_{2}$ and endocannabiniods) and neuropeptides/hormones (e.g., ghrelin, estrogen) arising from outside the VTA influence dopamine function as well (Becker, 1999; Chen et al., 2001; Cone et al., 2015; Munro et al., 2006; Oleson et al., 2012a; Oleson and Cheer, 2012; Oleson et al., 2014; Prast and Philippu, 2001; West et al., 2002). Investigating the role dopamine plays in behavior is further complicated by the growing recognition that dopamine neurons co-release multiple primary neurotransmitters, including GABA and glutamate (Stuber et al., 2010; Sulzer and Rayport, 2000; Tritsch et al., 2012). While co-release was thought to play exclusive roles in early development, including circuit formation and synaptic fortification, we are beginning to recognize that this form of neurotransmission continues to modify existing circuits and synapses into adulthood (Vaaga et al., 2014). And, even if we come to understand the precise impacts of co-release and neuromodulation, we must accept that dopamine function is shaped by its interactions within a wide array of neural networks. Indeed, neural input into the VTA greatly influences dopamine release (Brown et al., 2017; Tian and Uchida, 2015), and the effects of dopamine release in the NAc are dictated by converging cortical, amygdalar, and hippocampal input (Brady and O'Donnell, 2004; Floresco et al., 2001).

When considering the role dopamine plays in behavior it is also important to recognize that dopamine neurons fire in one of two distinct patterns. When at rest, dopamine neurons exhibit regular pacemaker activity $(1-5 \mathrm{~Hz})$ that produces a tone on high-affinity dopamine receptors (Goto and Grace, 2005; Venton et al., 2003). When presented with motivationally salient stimuli, dopamine neurons fire in phasic bursts ( $\geq 20 \mathrm{~Hz}$ ) (Goto and Grace, 2005). These bursts of neural activity contribute to transient release events that are sufficient in concentration to occupy low-affinity dopamine receptors (Dreyer et al., 2010; Sombers et al., 2009; Venton et al., 2003). This review will exclusively focus on the phasic form of dopamine release. While it is likely that the magnitude of release events in the NAc reflects the summation of phasic activity in the VTA (Sombers et al., 2009), it is noteworthy that dopamine neurons within the midbrain heterogeneously represent aversive stimuli at the level of the single unit (Lammel et al., 2012; Pignatelli and Bonci, 2015). Although the majority of electrophysiological studies report that dopamine neurons are inhibited by aversive stimuli (Mileykovskiy and Morales, 2011; Tan et al., 2012), there are numerous 
reports of excitations as well (Anstrom et al., 2009; Brischoux et al., 2009; Matsumoto and Hikosaka, 2009). Despite the fact that some of these results might be confounded by the inclusion of non-dopamine neurons (Ungless and Grace, 2012), they support the growing belief that many factors influence whether dopamine neurons are excited or inhibited by an aversive event - including the subpopulation of neurons surrounding the recording electrode (Lammel et al., 2012) and the environmental context in which aversion is introduced (Matsumoto et al., 2016).

In fact, variables such as environmental context and behavioral history greatly influence the emotional valence of stimuli at the behavioral level. Indeed, whether a stimulus is perceived to be rewarding or aversive by an individual subject is malleable and influenced by variables such as history and environment context (Nasser and McNally, 2012). Although electrical shock is generally assumed to be an aversive stimulus, animals can be trained to respond for its delivery (McKearney, 1968). Similarly, universally recognized rewarding stimuli, including abused drugs, can produce aversive responses (Grigson, 1997). These observations do not however, mean we should revert to ignoring emotional valence as was done in the historical behavioral analysis literature (Baron and Galizio, 2005). Rather, it should be acknowledged that the emotional valence of 'rewarding' and 'aversive' stimuli can change, and caution should be exercised during the design and analysis of studies on the neuroscience of motivation and emotion. While we are generations away from completely understanding how subpopulations of dopamine neurons interact at the pathway and network level to control rewarding vs. aversively motivated behavior, recent neuroscientific advances provide considerable insight into the role that transient dopamine release events play in guiding advantageous outcomes.

\section{Accumbal dopamine release in reward directed behavior}

By performing in vivo electrophysiological recordings in the midbrain of awake and behaving monkeys, Schultz et al. (1997) first demonstrated that putative dopamine neurons fire in phasic bursts when animals are presented with an unexpected reward or a reward predictive stimulus but are suppressed when an expected reward is withheld. This observation led to the prominent reward prediction error (RPE) theory, which holds that phasic bursts of dopamine neural activity encode a reward prediction signaled by the earliest predictor of its availability. While we now recognize that the traditional electrophysiological criteria used to identify dopamine neurons produced false positives (Ungless and Grace, 2012), many different labs have since used a variety of techniques to confirm the general precepts of RPE (Abler et al., 2006; Daw and Doya, 2006; Hart et al., 2014; Pagnoni et al., 2002).

By performing fast-scan cyclic voltammetry (FSCV), an electrochemical technique that allows for the detection of subsecond changes in dopamine release, we (Oleson et al., 2012a) confirmed that RPE can occur within a single brain stimulation reward session (OwessonWhite et al., 2008) (Fig. 1A-C). Here, we measured subsecond changes in dopamine release as rats pressed a lever that delivered electrical current into the VTA (i.e., brain stimulation reward). These electrical currents lead to the depolarization of dopamine neurons, albeit indirectly. Rather than directly activating dopamine neurons or their unmyelinated axons, 
dopamine neurons are thought to integrate input from non-dopaminergic pathways that can be directly activated by electrical stimulation (Hernandez et al., 2010; Moisan and Rompre, 1998). As a result of this integration, dopamine neurons burst fire to produce highconcentration, transient release events in terminal fields of the mesocorticolimbic pathway (Sombers et al., 2009).

Within each trial of the task, reward availability was signaled by a cue-light placed above the operant lever. When given the opportunity to respond on a lever that delivers electrical currents to the VTA, animals rapidly acquire responding within a single session (Fig. 1D). As would be predicted by RPE, the concentration of dopamine time-locked to a reward predictive cue increased as the latency to respond decreased (Fig. 1C, D). It is also noteworthy that dopamine concentration can increase prior to cue presentation when animals are able to anticipate the timing of reward availability (Cheer et al., 2007). Fig. 1A, B depicts these anticipatory dopamine responses preceding a reward predictive cue that was presented according to a fixed schedule. In such cases, dopamine may represent interoceptive timing cues, which are known to exert considerable power over ongoing behavior (Lake et al., 2016). Because dopamine release begins to occur at the earliest predictor of reward, it became widely accepted that these transient release events function as teaching signals to guide reward learning (Schultz et al., 1997). This causal relationship was first demonstrated by Adamantidis et al. (2011), who implemented optogenetics technology to show that increasing dopamine release at reward delivery accelerates reward learning.

\section{Transition from RPE to value signals}

RPE is currently being considered within the context of reward value. Reconsidering RPEassociated phasic dopamine release events as value signals provides the most parsimonious description of how DA functions within this behavioral context. The initial RPE studies were inspired by the fundamental classical conditioning studies of Pavlov and Rescorla-Wagner (Pavlov, 2010; Rescorla and Wagner, 1972), and, therefore, focused on the formation of conditioned associations through associative learning. From this perspective, it might be tempting to assume that with repeated associations between a reward and its predictive cue, that DA release will begin to exclusively occur at the earliest predictor of reward. While the data presented herein will show that DA release events tend to be higher in concentration at the predictive cue, they continue to occur at the outcome as well. In addition, while stimulus-response associations are important, they fail to completely account for the patterns of DA release observed during reinforced behavior. As will be discussed throughout this review, various factors influence DA release as animals pursue desired outcomes, including the timing of reinforcement delivery (Fonzi et al., 2017; Lake et al., 2016; Meck, 1986; Oleson et al., 2014), the motivational/emotional state of the animal (Cone et al., 2016), and the environment in which reinforcement is provided (Nakahara et al., 2004). Thus, a more apt description might be that DA release events guide animals to highly-valued outcomes in a state- and contextually-dependent manner. In this review, we will present data supporting that the DA signal evoked by a routinely presented reward-predictive stimulus reflects predicted value; whereas, the DA signal evoked by the outcome reflects experienced value. It is also worth noting that the field shifting toward a value-based framework was greatly influenced by computational assessments on the role of DA in reinforcement learning. An 
interdisciplinary combination of economic theory, computer science and mathematics led to value-based computational models that better align with the DA and behavioral observations we observe during action-outcome learning (Glimcher, 2011).

A growing body of electrophysiological and electrochemical studies suggest that the concentration of dopamine evoked by reward predictive cues corresponds to the magnitude of reward predicted by the cue (Bayer and Glimcher, 2005; Day et al., 2010; Day et al., 2011; Enomoto et al., 2011; Lak et al., 2014; Schelp et al., 2017; Stauffer et al., 2014; Tobler et al., 2005). Imaging studies reveal similar observations in human subjects and further refine the output regions involved. The BOLD signal in the VTA corresponds to RPE (KleinFlügge et al., 2011) but disparate effects are observed across striatal output regions. KleinFlügge et al., 2011 report that BOLD activity in the NAc encodes variables related to the receipt of reward, such as time of reward delivery, rather than RPE itself. This is an important distinction to consider in its own right. Using FSCV, we also find that changes in dopamine release events in the NAc are primarily related to time under conditions of periodic reinforcement, such as reward seeking maintained on a fixed-interval schedule (Oleson et al., 2014). Together, we interpret these results to suggest that dopamine release events play multiple roles in ongoing behavior rather than an exclusive role in RPE. Despite these potentially confounding time-related signals, multiple human imaging studies report that the BOLD signal in the ventral striatum (aka NAc in rats) and caudate (aka dorsal medial striatum in rats), but not the putamen (aka lateral medial striatum in rats) corresponds to RPE in humans (Haruno and Kawato, 2006a; Haruno and Kawato, 2006b; McClure et al., 2003; O'Doherty et al., 2003). Thus, a large body of evidence obtained using a variety of approaches supports the conception that cue-evoked dopamine release events actually represent a value prediction signaled by the cue (Schultz et al., 2015; Schultz et al., 2017). This shift in thought is leading investigators to incorporate elements of economic theory to investigate the relationship between dopamine and valuation (Arvanitogiannis and Shizgal, 2008; Burke et al., 2016; Hernandez et al., 2012; Pasquereau and Turner, 2013; Schultz et al., 2015). For example, a recent series of electrophysiological studies reported that dopamine neurons respond to gambles and outcomes to guide economic decisions (Stauffer et al., 2014), and are able to integrate various factors that underlie value (Lak et al., 2014).

\section{Using demand curves to investigate natural reward value}

We measure value by assessing the rate at which demand curves decay (Fig. 2). Demand curves are a common tool used by economists to measure price sensitivity. They depict the relationship between consumption ( $\mathrm{mg}$ of sugar received or $\mathrm{mA}$ footshock avoided, in this review) and price. In operant studies, price can be defined as the response requirement per unit reward (Bickel et al., 1990). Demand curves usually show a negative gradient (i.e., the law of demand), where consumption decreases with increasing price. The rate at which the negative slope decays can be used to make inferences regarding the value individuals place on the commodity being consumed. We fit demand curves using freely available R-studio programs (https://gitlab.com/oleson/schelp-pnas) and measure the price elasticity of demand by computing the variable $a$, an established dependent measure of value (Hursh and Silberberg, 2008). This variable represents the cost at which the elasticity of demand is exactly -1 , meaning consumption drops by one percent in response to a one percent increase 
in price. When demand curves decay at a faster rate they are said to be more elastic. A higher a value indicates the demand for the desired outcome is more elastic, suggesting the value of the commodity is diminished. In contrast, a lower a value indicates the demand for the commodity is relatively inelastic, suggesting the value of the commodity is enhanced (Fig. 2).

While the fields of psychopharmacology (Bickel et al., 1990) and behavioral analysis (Herrnstein, 1974) have a long history of applying demand curve analysis, the predominance of 'between-sessions' approaches has made it difficult to reliably perform neuroscientific assessments within daily sessions. We overcame this obstacle by developing a within-session approach that allows demand curves to be generated in daily sessions. Working within a behavioral economics framework, we first designed a 'between-sessions' procedure where rats were presented with cocaine at different prices across daily sessions (Oleson and Roberts, 2009). One unique feature of this approach is that we manipulated price by reducing the amount of drug delivered per lever press (Zittel-Lazarini et al., 2007). As the unit price ratio (lever presses required per unit of desired outcome) might suggest, unit price can be manipulated not only by increasing response requirement as in the progressive ratio schedule, but also by fixing the response requirement at 1 and decreasing the available unit of reward (Bickel et al., 1990). This latter approach reduces the temporal confound of opportunity cost that is inherent to tasks that manipulate price by increasing response requirement (Schelp et al., 2017), and allows the investigator to seamlessly change unit-price within daily sessions. The 'within-session' behavioral economics approach has several advantages over comparable tasks. Unlike the commonly used progressive ratio schedule, within-session behavioral economic tasks involve multiple pairings between each unit-price, reward and its predictive cue. These cue-associations are critically important for the cue to represent reward value and evoke lawful dopamine value signals. An additional benefit is that session duration is malleable, allowing the investigator to tailor their experimental design around commonly encountered temporal constraints (e.g., drug half-life, postreinforcement pauses, fatigue, etc.). Finally, behavioral economics uses common semantics that may facilitate interdisciplinary collaboration.

\section{Dopamine encodes reward value and causally modifies the price rats will pay for reward}

To test the revised value-based theory of RPE we performed demand analyses while rats responded on a lever for sugar. We reasoned that if transient dopamine signals do indeed represent value, then the transient dopamine response should be sensitive to price and modulating dopamine release should alter the rate at which demand curves decay. Access to sugar was provided across ten unit prices (defined as lever presses required per $\mathrm{mg}$ of sucrose) within a single session, with each price presented for a fixed epoch of time. A predictive cue light placed above the lever signaled sugar availability. We manipulated price by either increasing response requirement and reducing reward magnitude in independent assessments. Regardless of how price was manipulated, the concentration of accumbal core dopamine time-locked to cue presentation and sucrose-delivery significantly decreased with increasing price (Fig. 3A). These data show that the concentration of transient dopamine 
release events represent price and support the theory that dopamine represents reward value. To assess the causal influence of dopamine on price sensitivity, we then optically augmented release during the task. Augmenting release at the reward predictive cue increased dopamine concentration at the cue (Fig. 3B), but reduced release at reward delivery (Fig. 3C). As might be predicted from the latter dopamine observation, increasing release at cue presentation also made demand for sugar more sensitive to price (Fig. 3D-F). From these observations, we infer that value is decreased because of a negative RPE (i.e., the animal receives less reward than expected). Conversely, enhancing dopamine at reward made demand less sensitive to price (Fig. 3D-F). We attribute this finding to a positive RPE, whereby the animal perceives they received a better value than anticipated. These data confirm and extend the notion that dopamine release events encode reward value, and further demonstrate that increasing dopamine release causally modifies price sensitivity.

\section{Accumbal dopamine in avoidance}

Given the field's emphasis on the role of dopamine in reward directed behavior, relatively less is known regarding dopamine's role in avoiding harm. The few studies on the subject suggest that avoidance requires dopamine signaling, particularly dopamine release into the NAc. Animals fail to acquire avoidance following 6-hydroxydopamine lesions of midbrain dopamine neurons, a deficit that is reversed by L-dopa treatment (Cooper et al., 1973; Zis et al., 1974). While multiple terminal fields of the mesocorticolimbic pathway are likely involved in avoidance, an abundance of evidence clearly demonstrates a role for striatal dopamine within the NAc. Dopamine terminal lesions in the NAc (McCullough et al., 1993) and dopamine receptor antagonists locally administered in the NAc (Arnt, 1982; Wadenberg et al., 1990) impair the avoidance of electrical footshock while genetic restoration of dopamine within the striatum of otherwise dopamine-deficient mice is necessary to maintain avoidance (Darvas et al., 2011). While dopamine in the striatum was necessary to maintain avoidance, dopamine in the amygdala was necessary for avoidance learning (Darvas et al., 2011). Within the context of the existing literature, these findings suggest that while the amygdala is critically important for aversively motivated learning (Ledoux and Muller, 1997; LeDoux, 2003), the striatum may be recruited later on during the maintenance and habituation of avoidance (Poremba and Gabriel, 1999).

Early attempts to monitor dopamine release during avoidance using microdialysis revealed that striatal dopamine concentration is increased during the avoidance of electrical footshock (McCullough et al., 1993). However, it remained unknown precisely when dopamine is released during avoidance. In a typical active avoidance experiment multiple footshocks, avoidance outcomes, escape outcomes, and safety periods occur over the course of commonly used microdialysis sample collection times (10-20 min).

\section{Transient dopamine release in avoidance, escape and conditioned fear}

To characterize dopamine release in the NAc core during conditioned avoidance we measured subsecond accumbal dopamine release events during behavior maintained in an active, signaled operant avoidance task (Oleson et al., 2012b). Within each experimental trial, a cue light was presented to the animal as a warning signal for $2 \mathrm{~s}$ prior to the delivery 
of recurring footshock. A response lever was simultaneously extended into the operant chamber when the warning signal was illuminated. Two outcomes were possible: avoidance and escape. Animals could produce an avoidance outcome by pressing the lever once during the initial $2 \mathrm{~s}$ warning period. If an avoidance response occurred, footshock delivery was prevented and the animal entered a 20 s safety period signaled by a tone. Animals could produce an escape outcome by failing to press the lever during the initial $2 \mathrm{~s}$ warning period. Thus, the animal must respond on the lever to terminate ongoing footshock. As in avoidance, after each escape response animals enter a 20 s safety period signaled by a tone.

Under these conditions, the concentration of dopamine evoked by the warning signal increased during avoidance, but decreased during escape (cf. Fig. 4A, B). In other words, the occurrence of accumbal dopamine release during warning signal presentation predicted whether or not the animals would successfully avoid footshock. These data suggest that accumbal dopamine release encodes cues predicting avoidance and may motivate incipient actions devoted to this advantageous outcome. Further microinjection studies revealed that dopamine likely facilitates avoidance by acting on low-affinity D1, rather than high-affinity D2 receptors in the NAc (Wenzel et al., 2018). In both avoidance and escape outcomes, dopamine release increased during the safety period (Fig. 4A, B). It is possible that the distinct responses observed at the warning signal and safety signal during escape/avoidance may contribute to avoidance learning (Oleson and Cheer, 2013). Recent evidence from Luo et al. (2018) supports this supposition. These investigators demonstrated that dopamine signals originating in the VTA during safety are necessary to reduce fear responses by engaging molecular mechanisms in the NAc shell (Luo et al., 2018).

By contrast, an attenuation in accumbal dopamine concentration may suppress ongoing goal-directed behavior (Kravitz et al., 2012). It is likely that the suppression in dopamine release observed in escape training may underlie equally adaptive species-specific freezing responses that are observed during operant avoidance (Bolles, 1970). If so, operant avoidance provides a highly-objective approach to study the neural mechanisms underlying distinct ethologically-relevant defensive behaviors, including: fear, escape, and avoidance. In agreement with Badrinarayan et al. (2012), we also observed a transient suppression in dopamine concentration in the NAc core during the extinction of fear memories using a more traditional fear conditioning approach. Here, inescapable footshock was first conditioned to an otherwise neutral tone. $24 \mathrm{hr}$ later the conditioned tone was replayed while we monitored changes in accumbal dopamine release. A tone-induced suppression in dopamine release (Fig. 4C) was only apparent in trials in which the animal froze upon its presentation (Oleson et al., 2012b). We recently expanded upon these findings by applying optogenetics technology to show that augmenting dopamine release during the fearassociated tone facilitates the extinction of conditioned freezing (Wenzel et al., 2018; Badrinarayan et al., 2012). 


\section{Using demand curves to investigate avoidance value: feasibility and additional observations on the role of dopamine in conditioned suppression}

While accumbal dopamine release appears to contribute to different defensive behaviors, it remains controversial whether transient dopamine signals represent the value of avoiding harm. A notable electro-physiology study recently reported that dopamine neurons predominately encode the value of reward rather than avoidance (Fiorillo, 2013). To assess whether accumbal dopamine release events represent the value of active avoidance, we performed demand analysis as rats avoided electrical footshock across a range of prices in daily operant sessions. Our approach builds upon emerging economic approaches designed to study the value of avoidance (Spiegler et al., 2018; Sweis et al., 2018). We defined unitprice as lever responses per $\mathrm{mA}$ current (resp./mA) and manipulated price by increasing the number of lever presses required to avoid in fixed epochs within each session. While this task produced lawful demand curves, they were uniquely hallmarked by an attenuation of consumption at session onset (cf. Fig. 3E vs Fig. 5A). Because this attenuation developed over training, we infer that it represents a learned suppression resulting from repeated training sessions that only terminate when the animal receives 15-20 consecutive footshocks. This suppression at session onset is not observed early in economic avoidance training (Fig. 5A) and was absent during behavior maintained under a simple fixed ratio 1 schedule FR1) (Oleson et al., 2012b; Wenzel et al., 2018). In these earlier simple reinforcement studies, daily sessions terminated after a fixed period of time rather than after a fixed number of consecutive footshock. Thus, session onset did not necessarily predict an aversive session terminus.

As in our investigations into the role of dopamine during escape and conditioned fear, the concentration of NAc core dopamine evoked by the warning signal was concurrently suppressed with behavior at session onset (Fig. 5B). Optogenetic stimulation of VTA dopamine neurons at successful avoidance rectified the conditioned suppression of consummatory behavior at session onset-further supporting the notion that mesolimbic dopamine release causally modifies this defensive response (Fig. 5C).

\section{Dopamine encodes avoidance value and causally modifies the price rats will pay to avoid}

Despite the initial suppression, consumption of avoidance generally conformed to the law of demand, allowing us to assess whether dopamine represents the value to avoid aversive outcomes (Pultorak et al., 2018). To evaluate the role of NAc core dopamine in the valuation of avoidance, we first employed FSCV to monitor dopamine evoked by the warning signal across a range of prices. As in reward motivated behavior, dopamine concentration at the warning signal decreased with price (Fig. 6A). Also, similarly to reward-directed behavior (Fig. 1A, B) (Cheer et al., 2007; Oleson et al., 2012a), we observed anticipatory dopamine signals emerging prior to the warning signal (Fig. 6A, inset). One distinction from our previous work is that dopamine at the warning decreased with price in both avoidance and escape outcomes. While Oleson et al. (2012b) reported a suppression in dopamine 
concentration and behavior when the warning signal resulted in escape rather than avoidance (Fig. 4A, B), animals were simply trained to avoid footshock under an FR1 schedule in up to $50 \%$ of trials $(\sim 6 \mathrm{~d})$. The economic avoidance task required approximately $30 \mathrm{~d}$ of training. Thus, it is possible that the warning signal no longer produces a conditioned suppression during escape outcomes after extended training.

We also analyzed how dopamine responses change with price during the safety period. The pattern of dopamine release during the safety period is distinct, as this period is not transient; rather, each safety period lasted $30 \mathrm{~s}$ in duration. Thus, to more accurately assess dopamine transient activity during the safety period, we analyzed the amplitude of individual transient events throughout this period. We found that concentration of dopamine released during safety decreased with price, but only in avoidance outcomes (Fig. 6B). We interpret these distinct outcome-specific responses to suggest that dopamine concentration prior to behavioral action was predictive of value; whereas, dopamine concentration following action was reflective of the outcomes value.

We next sought to assess the causal role of dopamine in the valuation of avoidance by employing optogenetics. As in reward motivated behavior (Fig. 3C-E), optically stimulating dopamine neurons in the VTA at the warning signal made rats more sensitive to price (Fig. 6C), consistent with a negative RPE. We infer that heightened release at cue presentation signaled an advantageous outcome, a prediction that was then violated by the occurrence of footshock. By contrast, optically increasing release at successful avoidance made animals less sensitive to price (Fig. 6D), consistent with a positive RPE. We infer that heightened release at successful avoidance signaled the outcome was better than predicted, indicating a good value worth seeking. These results support the theory that transient dopamine signals causally influence valuation and further clarify that these value signals not only represent the value of pursuing reward, but also the value of avoiding harm.

\section{How does DA interact with other circuits that mediate avoidance?}

While our data suggest that DA release events are involved in both the valuation or reward and avoidance, it is likely that the mesolimbic DA pathway is merely a shared component of larger diverging circuits that ultimately control these distinct behaviors. Thus, we next consider several other brain regions implemented in avoidance and how these circuit nodes may interact with DA value signals. Within the striatum DA primarily acts on the predominate cell type present, GABAergic medium spiny neurons. These neurons then project to the globus pallidus - the primary output nucleus of the basal ganglia. For a thorough review on the role of the globus pallidus in aversion we refer the reader to (Wulff et al., 2018). The globus pallidum was traditionally divided into an internal segment that is associated with action initiation, and an external segment that is often associated with action inhibition (Stephenson-Jones et al., 2013). While these nuclei are clearly involved in defensive behaviors including avoidance, we are beginning to recognize the behavioral importance of a unique subset of habenula-projecting globus pallidal neurons (StephensonJones et al., 2016). Habenula-projecting globus pallidal neurons effectively close a valuation loop by conveying value signals from the striatum to the habenula, a structure well-known to indirectly inhibit dopamine neurons in the VTA (Stephenson-Jones, 2019; Tian and Uchida, 
2015). DA release events may directly influence these pallidal value signals during avoidance as local administration of DA D1R and D2R agonists into this region facilitates inhibitory avoidance learning (Lénárd et al., 2017; Péczely et al., 2014). Outside of the canonical basal ganglia extra-pyramidal motor pathway, amygdalar interactions between the amygdala and NAc are well known to influence avoidance. Of its three major subdivisions, the basal and medial, but not central amygdala are required for active avoidance (LázaroMuñoz et al., 2010). In well trained animals, the warning signal is thought to activate neurons in the lateral amygdala. These lateral amygdala neurons project to the basolateral amygdala which in turn projects to the NAc to influence active avoidance (LeDoux and Daw, 2018). By contrast, a distinct circuit involving the central amygdala and periaqueductal gray is thought to mediate a competing fear-induced freezing response (Johansen et al., 2011). It is possible that this latter 'fear' circuit contributes to the cue-evoked suppression in DA release observed early in avoidance learning and that the initial attenuation in avoidance observed in the within-session economic avoidance task. Indeed, optogenetic activation of the periaqueductal gray produces defensive escape-like responses that we believe contribute to these suppressed responses (Assareh et al., 2016) in addition to the aforementioned habenula. The prefrontal cortex is thought to mediate the switch from the central amygdalaperiaqueductal gray mediated freezing response and the basolateral amygdala-NAc mediated active avoidance response (LeDoux and Daw, 2018; Moscarello and LeDoux, 2013). Of the various regions that make up the prefrontal cortex, the orbitofrontal cortex seems to be particularly important for aversive learning (Jean-Richard-dit-Bressel and McNally, 2016). While dopamine concentration within the prefrontal cortex may play a particularly important role in active avoidance, the data presented herein suggest that it is not an exclusive one.

\section{Concluding statement}

In this review we describe how our recent behavioral economic investigations fit into the existing literature on the role of dopamine in appetitively and aversively motivated behavior. By performing demand analyses on operant data, we confirm that dopamine causally modifies the valuation of reward. However, we also demonstrate that dopamine plays a role in aversively-motivated defensive behaviors, including: avoidance, escape, and conditioned freezing. These observations support a more nuanced role for dopamine in adaptive behavior. Few neurochemicals serve a single behavioral function like reward processing. Rather, the evolutionarily-conserved mesocorticolimbic dopamine pathway was likely selected because it promotes an array of advantageous behaviors by integrating experience with emotion. What remains unknown is when, where, and how dopamine release mediates these distinctly advantageous behaviors. As this special issue will attest, various groups report that dopamine is released into different neural substrates at different times by a variety of appetitively- and aversively-associated stimuli. While many studies are required before a consensus is reached, recent advances in behavioral design, neural monitoring, and computational analysis will ensure we know exponentially more on the role dopamine plays in aversion ten years into the future than we knew ten years ago. 


\section{Funding}

Funding for this work was provided by NSF grant IOS-1557755, NIH grant R03DA038734, Boettcher Young Investigator Award and NARSAD Young Investigator Award to EBO.

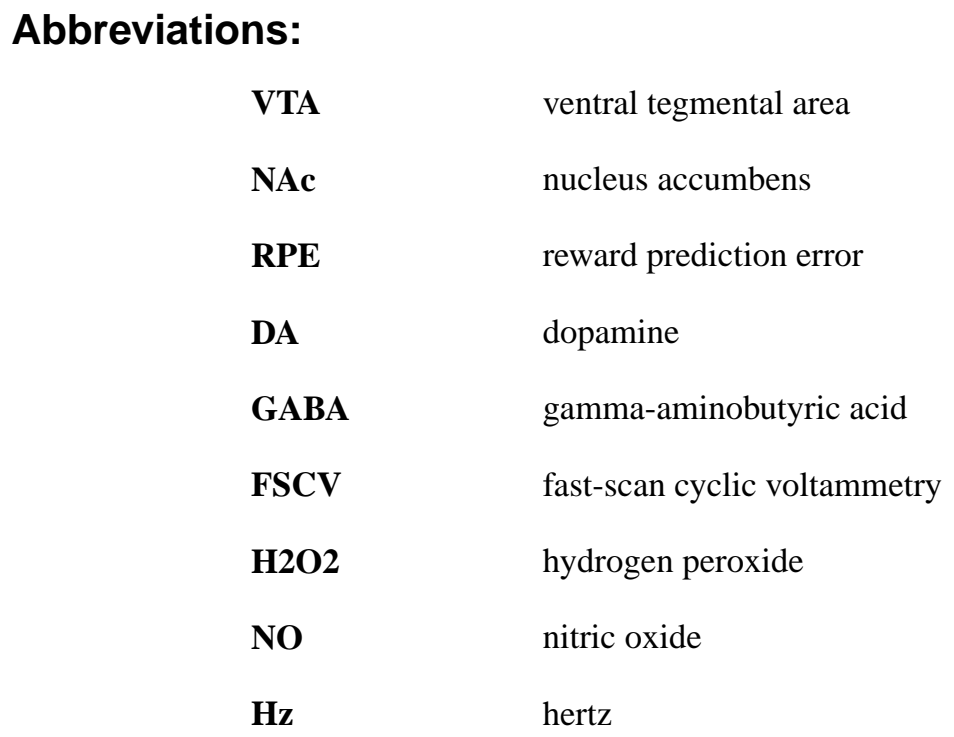

\section{Reference}

Abler B, Walter H, Erk S, Kammerer H, Spitzer M, 2006 Prediction error as a linear function of reward probability is coded in human nucleus accumbens. Neuroimage 31, 790-795. [PubMed: 16487726]

Adamantidis AR, Tsai H-C, Boutrel B, Zhang F, Stuber GD, Budygin EA, Touriño C, Bonci A, Deisseroth K, de Lecea L, 2011 Optogenetic interrogation of dopaminergic modulation of the multiple phases of reward-seeking behavior. J. Neurosci 31, 10829-10835. [PubMed: 21795535]

Anstrom KK, Miczek KA, Budygin EA, 2009 Increased phasic dopamine signaling in the mesolimbic pathway during social defeat in rats. Neuroscience 161, 3-12. [PubMed: 19298844]

Arnt J, 1982 Pharmacological specificity of conditioned avoidance response inhibition in rats: inhibition by neuroleptics and correlation to dopamine receptor blockade. Basic Clin. Pharmacol. Toxicol 51, 321-329.

Arvanitogiannis A, Shizgal P, 2008 The reinforcement mountain: allocation of behavior as a function of the rate and intensity of rewarding brain stimulation. Behav. Neurosci 122, 1126. [PubMed: 18823168]

Assareh N, Sarrami M, Carrive P, McNally GP, 2016 The organization of defensive behavior elicited by optogenetic excitation of rat lateral or ventrolateral periaqueductal gray. Behav. Neurosci 130, 406. [PubMed: 27243807]

Badrinarayan A, Wescott SA, Vander Weele CM, Saunders BT, Couturier BE, Maren S, Aragona BJ, 2012 Aversive stimuli differentially modulate real-time dopamine transmission dynamics within the nucleus accumbens core and shell. J. Neurosci 32, 15779-15790. [PubMed: 23136417]

Baron A, Galizio M, 2005 Positive and negative reinforcement: Should the distinction be preserved? Behavior Analyst. 28, 85-98. [PubMed: 22478443]

Bayer HM, Glimcher PW, 2005 Midbrain dopamine neurons encode a quantitative reward prediction error signal. Neuron 47, 129-141. [PubMed: 15996553]

Becker JB, 1999 Gender differences in dopaminergic function in striatum and nucleus accumbens. Pharmacol. Biochem. Behav 64, 803-812. [PubMed: 10593204]

Bickel WK, DeGrandpre RJ, Higgins ST, Hughes JR, 1990 Behavioral economics of drug selfadministration. I. Functional equivalence of response requirement and drug dose. Life Sci. 47, 1501-1510. [PubMed: 2250566] 
Bolles RC, 1970 Species-specific defense reactions and avoidance learning. Psychol. Rev 77, 32.

Bouchet CA, Miner MA, Loetz EC, Rosberg AJ, Hake HS, Farmer CE, Ostrovskyy M, Gray N, Greenwood BN, 2018 Activation of nigrostriatal dopamine neurons during fear extinction prevents the renewal of fear. Neuropsychopharmacology 43, 665. [PubMed: 28976945]

Brady AM, O’Donnell P, 2004 Dopaminergic modulation of prefrontal cortical input to nucleus accumbens neurons in vivo. J. Neurosci 24, 1040-1049. [PubMed: 14762122]

Brischoux F, Chakraborty S, Brierley DI, Ungless MA, Graybiel AM, 2009 Phasic excitation of dopamine neurons in ventral VTA by noxious stimuli. Proc. Natl. Acad. Sci 106, 4894-4899. [PubMed: 19261850]

Brown PL, Palacorolla H, Brady D, Riegger K, Elmer GI, Shepard PD, 2017 Habenula-induced inhibition of midbrain dopamine neurons is diminished by lesions of the rostromedial tegmental nucleus. J. Neurosci 37, 217-225. [PubMed: 28053043]

Burke CJ, Baddeley M, Tobler PN, Schultz W, 2016 Partial adaptation of obtained and observed value signals preserves information about gains and losses. J. Neurosci 36, 10016-10025. [PubMed: 27683899]

Cardinal RN, Parkinson JA, Hall J, Everitt BJ, 2002 Emotion and motivation: the role of the amygdala, ventral striatum, and prefrontal cortex. Neurosci. Biobehav. Rev 26, 321-352. [PubMed: 12034134]

Cheer JF, Aragona BJ, Heien ML, Seipel AT, Carelli RM, Wightman RM, 2007 Coordinated accumbal dopamine release and neural activity drive goal-directed behavior. Neuron 54, 237-244. [PubMed: 17442245]

Chen BT, Avshalumov MV, Rice ME, $2001 \mathrm{H} 2 \mathrm{O} 2$ is a novel, endogenous modulator of synaptic dopamine release. J. Neurophysiol 85, 2468-2476. [PubMed: 11387393]

Cone JJ, Roitman JD, Roitman MF, 2015 Ghrelin regulates phasic dopamine and nucleus accumbens signaling evoked by food-predictive stimuli. J. Neurochem 133, 844-856. [PubMed: 25708523]

Cone JJ, Fortin SM, McHenry JA, Stuber GD, McCutcheon JE, Roitman MF, 2016 Physiological state gates acquisition and expression of mesolimbic reward prediction signals. Proc. Natl. Acad. Sci 113, 1943-1948. [PubMed: 26831116]

Cooper BR, Breese GR, Grang LD, Howard JL, 1973 Effects of 6-hydroxydopamine treatments on active avoidance responding: evidence for involvement of brain dopamine. J. Pharmacol. Exp. Ther 185, 358-370. [PubMed: 4703827]

Darvas M, Fadok JP, Palmiter RD, 2011 Requirement of dopamine signaling in the amygdala and striatum for learning and maintenance of a conditioned avoidance response. Learn. Memory 18, 136-143.

Daw ND, Doya K, 2006 The computational neurobiology of learning and reward. Curr.Opin. Neurobiol 16, 199-204. [PubMed: 16563737]

Day JJ, Jones JL, Wightman RM, Carelli RM, 2010 Phasic nucleus accumbens dopamine release encodes effort-and delay-related costs. Biol. Psychiatry 68, 306-309. [PubMed: 20452572]

Day JJ, Jones JL, Carelli RM, 2011 Nucleus accumbens neurons encode predicted and ongoing reward costs in rats. Eur. J. Neurosci 33, 308-321. [PubMed: 21198983]

Dreyer JK, Herrik KF, Berg RW, Hounsgaard JD, 2010 Influence of phasic and tonic dopamine release on receptor activation. J. Neurosci 30, 14273-14283. [PubMed: 20962248]

Enomoto K, Matsumoto N, Nakai S, Satoh T, Sato TK, Ueda Y, Inokawa H, Haruno M, Kimura M, 2011 Dopamine neurons learn to encode the long-term value of multiple future rewards. Proc. Natl. Acad. Sci 108, 15462-15467. [PubMed: 21896766]

Fiorillo CD, 2013 Two dimensions of value: dopamine neurons represent reward but not aversiveness. Science 341, 546-549. [PubMed: 23908236]

Floresco SB, Todd CL, Grace AA, 2001 Glutamatergic afferents from the hippocampus to the nucleus accumbens regulate activity of ventral tegmental area dopamine neurons. J. Neurosci 21, 49154922. [PubMed: 11425919]

Fonzi KM, Lefner MJ, Phillips PE, Wanat MJ, 2017 Dopamine encodes retrospective temporal information in a context-independent manner. Cell reports. 20, 1765-1774. [PubMed: 28834741]

Glimcher PW, 2011 Understanding dopamine and reinforcement learning: the dopamine reward prediction error hypothesis. Proc. Natl. Acad. Sci 108, 15647-15654. [PubMed: 21389268] 
Goto Y, Grace AA, 2005 Dopaminergic modulation of limbic and cortical drive of nucleus accumbens in goal-directed behavior. Nat. Neurosci 8, 805. [PubMed: 15908948]

Grigson PS, 1997 Conditioned taste aversions and drugs of abuse: a reinterpretation.Behav. Neurosci. $111,129$.

Groessl F, Munsch T, Meis S, Griessner J, Kaczanowska J, Pliota P, Kargl D, Badurek S, Kraitsy K, Rassoulpour A, Zuber J, Lessmann V, Haubensak W, 2018 Dorsal tegmental dopamine neurons gate associative learning of fear. Nat Neurosci. Epub

Hart AS, Rutledge RB, Glimcher PW, Phillips PE, 2014 Phasic dopamine release in the rat nucleus accumbens symmetrically encodes a reward prediction error term. J. Neurosci 34, 698-704. [PubMed: 24431428]

Haruno M, Kawato M, 2006a Different neural correlates of reward expectation and reward expectation error in the putamen and caudate nucleus during stimulus-action-reward association learning. J. Neurophysiol 95, 948-959. [PubMed: 16192338]

Haruno M, Kawato M, 2006b Heterarchical reinforcement-learning model for integration of multiple cortico-striatal loops: fMRI examination in stimulus-action-reward association learning. Neural Networks 19, 1242-1254. [PubMed: 16987637]

Hernandez G, Breton Y-A, Conover K, Shizgal P, 2010 At what stage of neural processing does cocaine act to boost pursuit of rewards? PLoS One 5, e15081. [PubMed: 21152097]

Hernandez G, Trujillo-Pisanty I, Cossette M-P, Conover K, Shizgal P, 2012 Role of dopamine tone in the pursuit of brain stimulation reward. J. Neurosci 32, 11032-11041. [PubMed: 22875936]

Herrnstein RJ, 1974 Formal properties of the matching law. J. Exp. Anal. Behav 21,159-164. [PubMed: 16811728]

Hursh SR, Silberberg A, 2008 Economic demand and essential value. Psychol. Rev115, 186. [PubMed: 18211190]

Jean-Richard-dit-Bressel P, McNally GP, 2016 Lateral, not medial, prefrontal cortex contributes to punishment and aversive instrumental learning. Learn. Memory 23, 607-617.

Johansen JP, Cain CK, Ostroff LE, LeDoux JE, 2011 Molecular mechanisms of fear learning and memory. Cell 147, 509-524. [PubMed: 22036561]

Klein-Flügge MC, Hunt LT, Bach DR, Dolan RJ, Behrens TE, 2011 Dissociable reward and timing signals in human midbrain and ventral striatum. Neuron 72, 654-664. [PubMed: 22099466]

Kravitz AV, Tye LD, Kreitzer AC, 2012 Distinct roles for direct and indirect pathway striatal neurons in reinforcement. Nat. Neurosci 15, 816. [PubMed: 22544310]

Lak A, Stauffer WR, Schultz W, 2014 Dopamine prediction error responses integrate subjective value from different reward dimensions. Proc. Natl. Acad. Sci 111, 2343-2348. [PubMed: 24453218]

Lake JI, LaBar KS, Meck WH, 2016 Emotional modulation of interval timing and time perception. Neurosci. Biobehav. Rev 64, 403-420. [PubMed: 26972824]

Lammel S, Lim B, Ran C, Huang K, Betley M, Tye K, Deisseroth K, Malenka R, 2012 Input-specific control of reward and aversion in the ventral tegmental area. Nature 491 212-212. [PubMed: 23064228]

Lázaro-Muñoz G, LeDoux JE, Cain CK, 2010 Sidman instrumental avoidance initially depends on lateral and basal amygdala and is constrained by central amygdala-mediated Pavlovian processes. Biol. Psychiatry 67, 1120-1127. [PubMed: 20110085]

LeDoux J, 2003 The emotional brain, fear, and the amygdala. Cell. Mol. Neurobiol 23, 727-738. [PubMed: 14514027]

LeDoux JE, Muller J, 1997 Emotional memory and psychopathology. Philosophical Transactions of the Royal Society of London. Series B: Biol. Sci 352, 1719-1726.

LeDoux J, Daw ND, 2018 Surviving threats: neural circuit and computational implications of a new taxonomy of defensive behaviour. Nat. Rev. Neurosci Neuroscience.

Lénárd L, Ollmann T, László K, Kovács A, Gálosi R, Kállai V, Attila T, Kertes E, Zagoracz O, Karádi Z, 2017 Role of D2 dopamine receptors of the ventral pallidum in inhibitory avoidance learning. Behav. Brain Res. 321, 99-105. [PubMed: 28057528]

Luo R, Uematsu A, Weitemier A, Aquili L, Koivumaa J, McHugh TJ, Johansen JP, 2018 A dopaminergic switch for fear to safety transitions. Nat. Commun 9, 2483. [PubMed: 29950562] 
Margolis EB, Toy B, Himmels P, Morales M, Fields HL, 2012 Identification of rat ventral tegmental area GABAergic neurons. PLoS One 7, e42365. [PubMed: 22860119]

Matsumoto M, Hikosaka O, 2009 Two types of dopamine neuron distinctly convey positive and negative motivational signals. Nature 459, 837-841. [PubMed: 19448610]

Matsumoto H, Tian J, Uchida N, Watabe-Uchida M, 2016 Midbrain dopamine neurons signal aversion in a reward-context-dependent manner. Elife 5.

McClure SM, Berns GS, Montague PR, 2003 Temporal prediction errors in a passive learning task activate human striatum. Neuron 38, 339-346. [PubMed: 12718866]

McCullough L, Sokolowski J, Salamone J, 1993 A neurochemical and behavioral investigation of the involvement of nucleus accumbens dopamine in instrumental avoidance. Neuroscience 52, 919925. [PubMed: 8450978]

McKearney JW, 1968 Maintenance of responding under a fixed-interval schedule of electric shockpresentation. Science 160, 1249-1251. [PubMed: 4967505]

Meck WH, 1986 Affinity for the dopamine D2 receptor predicts neuroleptic potency in decreasing the speed of an internal clock. Pharmacol. Biochem. Behav 25, 1185-1189. [PubMed: 2880350]

Mika A, Bouchet CA, Bunker P, Hellwinkel JE, Spence KG, Day HE, Campeau S, Fleshner M, Greenwood BN, 2015 Voluntary exercise during extinction of auditory fear conditioning reduces the relapse of fear associated with potentiated activity of striatal direct pathway neurons. Neurobiol. Learn. Mem 125, 224-235. [PubMed: 26454156]

Mileykovskiy B, Morales M, 2011 Duration of inhibition of ventral tegmental area dopamine neurons encodes a level of conditioned fear. J. Neurosci 31, 7471-7476. [PubMed: 21593330]

Mogenson GJ, Jones DL, Yim CY, 1980 From motivation to action: functional interface between the limbic system and the motor system. Prog. Neurobiol 14, 69-97. [PubMed: 6999537]

Moisan J, Rompre P-P, 1998 Electrophysiological evidence that a subset of midbrain dopamine neurons integrate the reward signal induced by electrical stimulation of the posterior mesencephalon. Brain Res. 786, 143-152. [PubMed: 9554987]

Morales M, Margolis E, 2017 Ventral tegmental area: cellular heterogeneity, connectivity and behaviour. Nat. Rev. Neurosci 18, 73-85. [PubMed: 28053327]

Moscarello JM, LeDoux JE, 2013 Active avoidance learning requires prefrontal suppression of amygdala-mediated defensive reactions. J. Neurosci 33, 3815-3823. [PubMed: 23447593]

Munro CA, McCaul ME, Wong DF, Oswald LM, Zhou Y, Brasic J, Kuwabara H, Kumar A, Alexander M, Ye W, 2006 Sex differences in striatal dopamine release in healthy adults. Biol. Psychiatry 59, 966-974. [PubMed: 16616726]

Nair-Roberts RG, Chatelain-Badie S, Benson E, White-Cooper H, Bolam J, Ungless M, 2008 Stereological estimates of dopaminergic, GABAergic and glutamatergic neurons in the ventral tegmental area, substantia nigra and retrorubral field in the rat. Neuroscience 152, 1024-1031. [PubMed: 18355970]

Nakahara H, Itoh H, Kawagoe R, Takikawa Y, Hikosaka O, 2004 Dopamine neurons can represent context-dependent prediction error. Neuron 41, 269-280. [PubMed: 14741107]

Nasser HM, McNally GP, 2012 Appetitive-aversive interactions in Pavlovian fear conditioning. Behav. Neurosci 126, 404. [PubMed: 22642885]

O’Doherty JP, Dayan P, Friston K, Critchley H, Dolan RJ, 2003 Temporal difference models and reward-related learning in the human brain. Neuron 38, 329-337. [PubMed: 12718865]

Oleson EB, Beckert MV, Morra JT, Lansink CS, Cachope R, Abdullah RA, Loriaux AL, Schetters D, Pattij T, Roitman MF, 2012a Endocannabinoids shape accumbal encoding of cue-motivated behavior via CB1 receptor activation in the ventral tegmentum. Neuron 73, 360-373. [PubMed: 22284189]

Oleson EB, Gentry RN, Chioma VC, Cheer JF, 2012b Subsecond dopamine release in the nucleus accumbens predicts conditioned punishment and its successful avoidance. J. Neurosci 32, 1480414808. [PubMed: 23077064]

Oleson EB, Cheer JF, 2012 A brain on cannabinoids: the role of dopamine release in reward seeking. Cold Spring Harb. Perspect. Med 2, a012229. [PubMed: 22908200]

Oleson EB, Cheer JF, 2013 On the role of subsecond dopamine release in conditioned avoidance. Front. Neurosci 7, 96. [PubMed: 23759871] 
Oleson EB, Cachope R, Fitoussi A, Tsutsui K, Wu S, Gallegos JA, Cheer JF, 2014 Cannabinoid receptor activation shifts temporally engendered patterns of dopamine release.

Neuropsychopharmacology. 39, 1441. [PubMed: 24345819]

Oleson EB, Roberts DC, 2009 Behavioral economic assessment of price and cocaine consumption following self-administration histories that produce escalation of either final ratios or intake. Neuropsychopharmacology. 34, 796. [PubMed: 18971927]

Owesson-White CA, Cheer JF, Beyene M, Carelli RM, Wightman RM, 2008 Dynamic changes in accumbens dopamine correlate with learning during intracranial self-stimulation. Proc. Natl. Acad. Sci 105, 11957-11962. [PubMed: 18689678]

Pagnoni G, Zink CF, Montague PR, Berns GS, 2002 Activity in human ventral striatum locked to errors of reward prediction. Nat. Neurosci 5, 97. [PubMed: 11802175]

Pasquereau B, Turner RS, 2013 Limited encoding of effort by dopamine neurons in a cost-benefit trade-off task. J. Neurosci 33, 8288-8300. [PubMed: 23658169]

Pavlov PI, 2010 Conditioned reflexes: an investigation of the physiological activity of the cerebral cortex. Ann. Neurosci 17, 136. [PubMed: 25205891]

Péczely L, Ollmann T, László K, Kovács A, Gálosi R, Szabó Á, Karádi Z, Lénárd L, 2014 Role of D1 dopamine receptors of the ventral pallidum in inhibitory avoidance learning. Behav. Brain Res. 270, 131-136. [PubMed: 24815313]

Pignatelli M, Bonci A, 2015 Role of dopamine neurons in reward and aversion: a synaptic plasticity perspective. Neuron 86, 1145-1157. [PubMed: 26050034]

Poremba A, Gabriel M, 1999 Amygdala neurons mediate acquisition but not maintenance of instrumental avoidance behavior in rabbits. J. Neurosci 19, 9635-9641. [PubMed: 10531465]

Prast H, Philippu A, 2001 Nitric oxide as modulator of neuronal function. Prog. Neurobiol 64, 51-68. [PubMed: 11250062]

Pultorak KJ, Schelp SA, Isaacs DP, Krzystyniak G, Oleson EB, 2018 A transient dopamine signal represents avoidance value and causally influences the demand to avoid. eNeuro. ENEURO 005818.2018.

Rescorla RA, Wagner AR, 1972 A theory of Pavlovian conditioning: Variations in the effectiveness of reinforcement and nonreinforcement. Classical conditioning II. Curr. Res. Theory 2, 64-99.

Schelp S, Pultorak K, Rakowski D, Gomez D, Krzystyniak G, Das R, Oleson EB, 2017 A transient dopamine signal encodes subjective value and causally influences demand in an economic context. Proc. Nat. Acad. Sci

Schultz W, Carelli RM, Wightman RM, 2015 Phasic dopamine signals: from subjective reward value to formal economic utility. Curr. Opin. Behav. Sci 5, 147-154. [PubMed: 26719853]

Schultz W, Dayan P, Montague PR, 1997 A neural substrate of prediction and reward. Science 275, 1593-1599. [PubMed: 9054347]

Schultz W, Stauffer WR, ArminLak, 2017 The phasic dopamine signal maturing: from reward via behavioural activation to formal economic utility. Curr. Opin. Neurobiol 43, 139-148. [PubMed: 28390863]

Smeets WJ, Marin O, Gonzalez A, 2000 Evolution of the basal ganglia: new perspectives through a comparative approach. J. Anat 196, 501-517. [PubMed: 10923983]

Sombers LA, Beyene M, Carelli RM, Wightman RM, 2009 Synaptic overflow of dopamine in the nucleus accumbens arises from neuronal activity in the ventral tegmental area. J. Neurosci 29 , 1735-1742. [PubMed: 19211880]

Spiegler KM, Fortress AM, Pang KC, 2018 Differential use of danger and safety signals in an animal model of anxiety vulnerability: The behavioral economics of avoidance. Prog. NeuroPsychopharmacol. Biol. Psychiatry 82, 195-204.

Stauffer WR, Lak A, Schultz W, 2014 Dopamine reward prediction error responses reflect marginal utility. Curr. Biol 24, 2491-2500. [PubMed: 25283778]

Stephenson-Jones M, 2019 Pallidal circuits for aversive motivation and learning. Curr. Opin. Behav. Sci 26, 82-89.

Stephenson-Jones M, Kardamakis AA, Robertson B, Grillner S, 2013 Independent circuits in the basal ganglia for the evaluation and selection of actions. Proc. Nat. Acad. Sci 201314815. 
Stephenson-Jones M, Yu K, Ahrens S, Tucciarone JM, van Huijstee AN, Mejia LA, Penzo MA, Tai LH, Wilbrecht L, Li B, 2016 A basal ganglia circuit for evaluating action outcomes. Nature 539, 289. [PubMed: 27652894]

Stuber GD, Hnasko TS, Britt JP, Edwards RH, Bonci A, 2010 Dopaminergic terminals in the nucleus accumbens but not the dorsal striatum corelease glutamate.J. Neurosci 30, 8229-8233. [PubMed: 20554874]

Sulzer D, Rayport S, 2000 Dale's principle and glutamate corelease from ventral midbrain dopamine neurons. Amino Acids 19, 45-52. [PubMed: 11026472]

Swanson L, 1982 The projections of the ventral tegmental area and adjacent regions: a combined fluorescent retrograde tracer and immunofluorescence study in the rat. Brain Res. Bull 9, 321353. [PubMed: 6816390]

Sweis BM, Thomas MJ, Redish AD, 2018 Mice learn to avoid regret. PLoS Biol. 16, e2005853. [PubMed: 29927938]

Tagliaferro P, Morales M, 2008 Synapses between corticotropin-releasing factor-containing axon terminals and dopaminergic neurons in the ventral tegmental area are predominantly glutamatergic. J. Comp. Neurol 506, 616-626. [PubMed: 18067140]

Tan KR, Yvon C, Turiault M, Mirzabekov JJ, Doehner J, Labouèbe G, Deisseroth K, Tye KM, Lüscher C, 2012 GABA neurons of the VTA drive conditioned place aversion. Neuron 73, 1173-1183. [PubMed: 22445344]

Tian J, Uchida N, 2015 Habenula lesions reveal that multiple mechanisms underlie dopamine prediction errors. Neuron 87, 1304-1316. [PubMed: 26365765]

Tobler PN, Fiorillo CD, Schultz W, 2005 Adaptive coding of reward value by dopamine neurons. Science 307, 1642-1645. [PubMed: 15761155]

Tritsch NX, Ding JB, Sabatini BL, 2012 Dopaminergic neurons inhibit striatal output through noncanonical release of GABA. Nature 490, 262. [PubMed: 23034651]

Ungless M, Grace A, 2012 Challenges associated with physiologically identifying dopamine neurons. Trends Neurosci. 35, 422-430. [PubMed: 22459161]

Vaaga CE, Borisovska M, Westbrook GL, 2014 Dual-transmitter neurons: functional implications of co-release and co-transmission. Curr. Opin. Neurobiol 29, 25-32. [PubMed: 24816154]

Venton BJ, Zhang H, Garris PA, Phillips PE, Sulzer D, Wightman RM, 2003 Real-time decoding of dopamine concentration changes in the caudate-putamen during tonic and phasic firing. $\mathrm{J}$. Neurochem 87, 1284-1295. [PubMed: 14622108]

Wadenberg M-L, Ericson E, Magnusson O, Ahlenius S, 1990 Suppression of conditioned avoidance behavior by the local application of (-) sulpiride into the ventral, but not the dorsal, striatum of the rat. Biol. Psychiatry 28, 297-307. [PubMed: 2144458]

Wenzel JM, Oleson EB, Gove WN, Cole AB, Gyawali U, Dantrassy HM, Bluett RJ, Dryanovski DI, Stuber GD, Deisseroth K, 2018 Phasic dopamine signals in the nucleus accumbens that cause active avoidance require endocannabinoid mobilization in the midbrain. Curr. Biol

West AR, Galloway MP, Grace AA, 2002 Regulation of striatal dopamine neurotransmission by nitric oxide: effector pathways and signaling mechanisms. Synapse. 44, 227-245. [PubMed: 11984858]

Wulff AB, Tooley J, Marconi LJ, Creed MC, 2018 Ventral pallidal modulation of aversion processing. Brain Res.

Yamaguchi T, Sheen W, Morales M, 2007 Glutamatergic neurons are present in the rat ventral tegmental area. Eur. J. Neurosci 25, 106-118. [PubMed: 17241272]

Zis AP, Fibiger HC, Phillips AG, 1974 Reversal by L-dopa of impaired learning due to destruction of the dopaminergic nigro-neostriatal projection. Science 185, 960-962. [PubMed: 4471715]

Zittel-Lazarini A, Cador M, Ahmed SH, 2007 A critical transition in cocaine self-administration: behavioral and neurobiological implications. Psychopharmacology. 192, 337-346. [PubMed: 17318508] 


\section{HIGHLIGHTS}

- Within an economic context DA causally modifies the price rats pay for reward.

- We also describe DA's roles in in avoidance, escape and conditioned fear.

- A new economics-based approach to assess the value of avoidance is described.

- In this context, DA causally modifies the price rats pay to avoid footshock. 
A
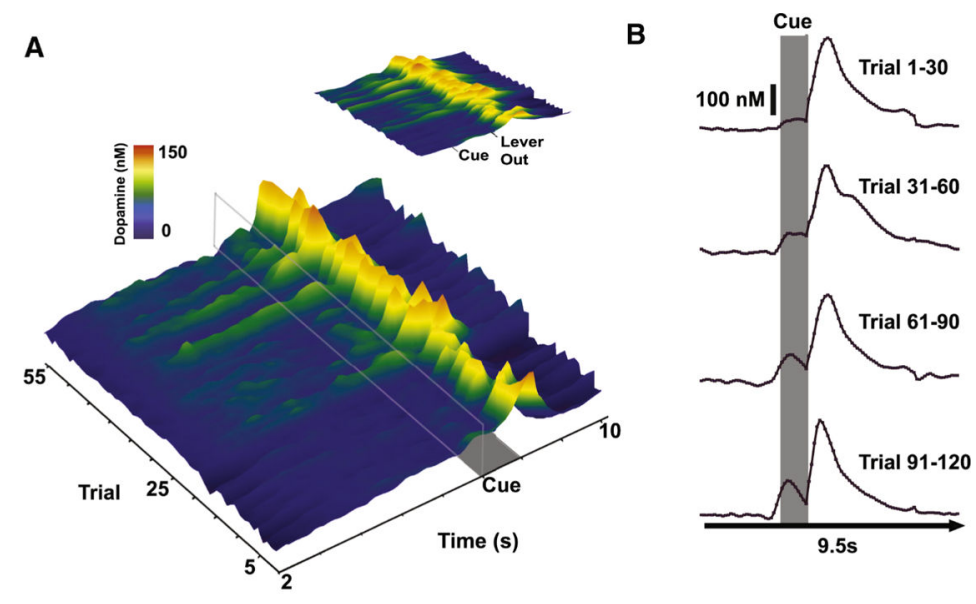

C

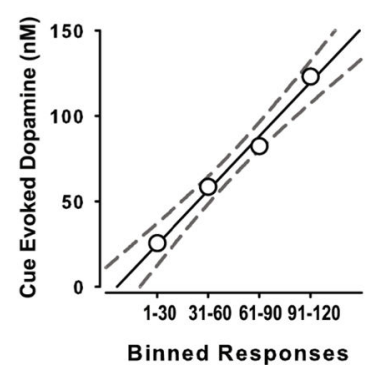

D

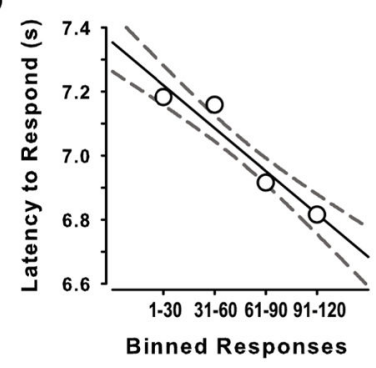

Fig. 1.

Republished from Oleson et al., 2012a with permission. (A) Pavlovian associations sculpt patterns of transient dopamine release in response to a predictive cue during reward seeking. A representative surface-plot shows changes in dopamine concentration (z-axis) occurring across trials (y-axis) while responding is maintained by brain stimulation reward in an ICSS task. Cue presentation, which is indicated by the gray rectangle, occurred for 1-s prior to lever extension. (B) Representative traces show the mean cue-evoked dopamine concentration increasing across trials. Each dopamine concentration trace represents the mean of 30 consecutive trials. (C, D) The conditioned cue begins to strengthen reward seeking as the concentration of cue-evoked dopamine increases across trials. Linear regression analyses show increases in mean dopamine concentration and decreases in response latency across binned responses. Dashed lines represent the $95 \%$ confidence region. 


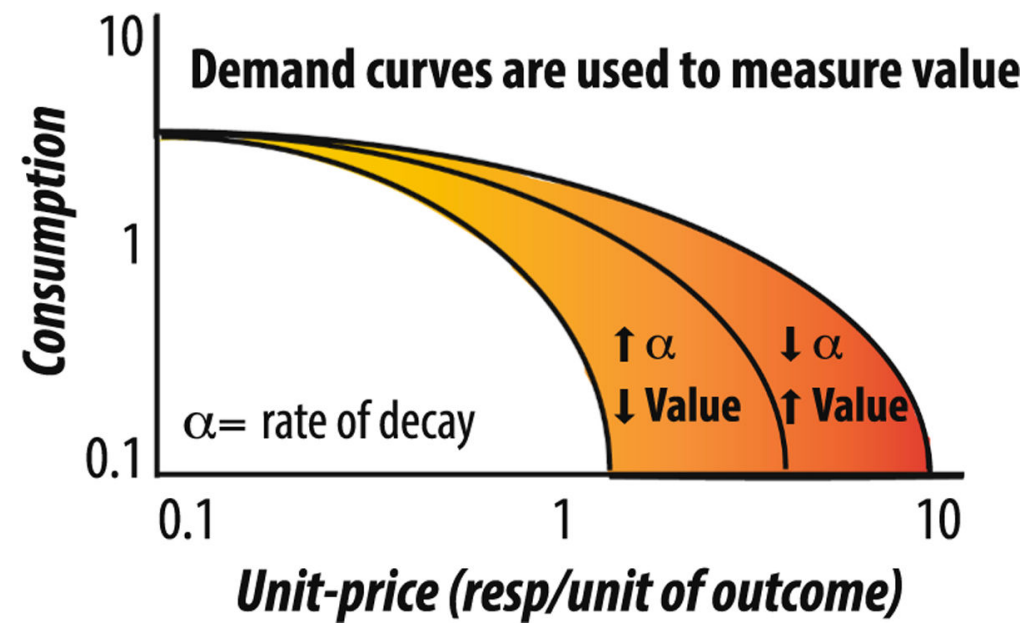

Fig. 2.

Measuring value: Illustrative demand curve showing how we determine value. $a$ is our dependent measure of value and represents the rate at which the demand curve decays. Demand decays at a faster rate when the animal becomes more sensitive to price. As the animal is willing to pay less for the commodity, we would interpret the resulting increase in $a$ as a decrease in value. 


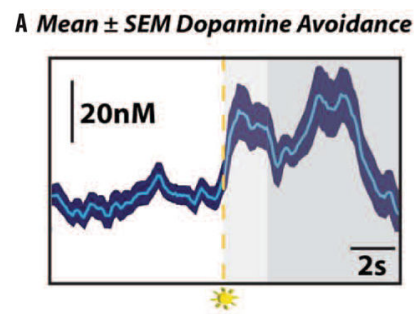

B Mean \pm SEM Dopamine Escape

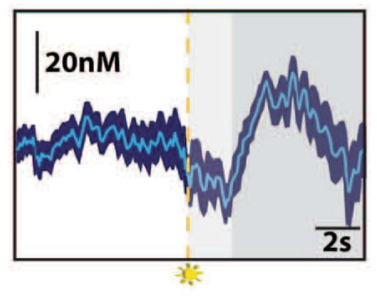

C Mean Dopamine: Conditioned fear

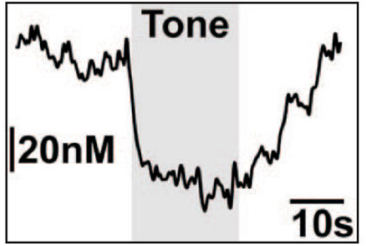

Fig. 3.

Republished from Schelp et al., 2017 with permission. (A) Dopamine concentration (mean \pm sem) decreases across the first five prices in the sugar-based behavioral economics task. (B, C) Optogenetic stimulation at cue increases dopamine release at cue but decreases dopamine release at reward delivery. When compared to baseline animals (A), stimulating dopamine release at cue presentation increased dopamine at cue $(\mathrm{B})$ but decreased dopamine at reward delivery (C). (D-F) Optogenetic stimulation alters price sensitivity in a representative rat.

(D) Cumulative records from one animal responding in sugar-based behavioral economics task. Colors denoting stimulation condition are shown in the legend. (E) The same data are re-plotted to show responses as a function of unit price. (F) Demand curves show consumption as a function of unit price. Demand curves are fitted to the data to estimate $a$. a measures price sensitivity; a high a values indicate consumption decays rapidly with price. 
A

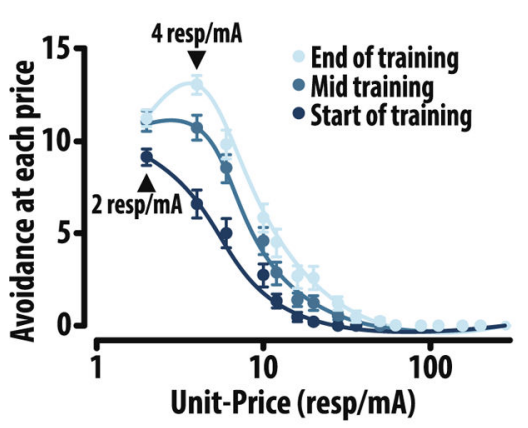

B

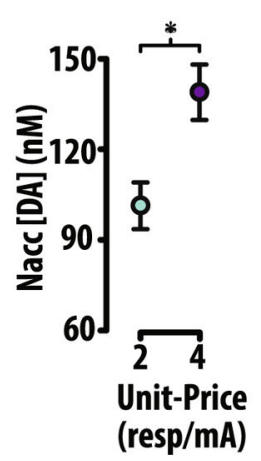

C 2 resp/mA

TH-Cre WT

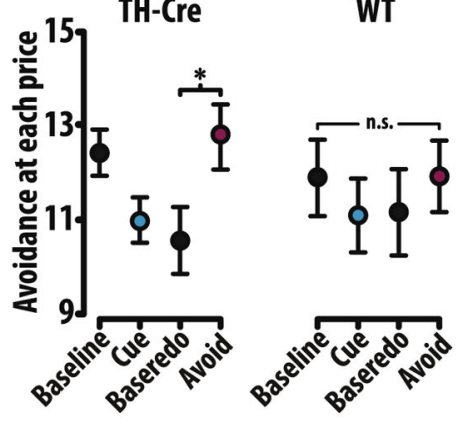

Fig. 4.

Republished from Oleson et al., 2012b with permission. (A) Dopamine encodes conditioned stimuli during negative reinforcement. Representative color plots (left) and dopamine concentration traces (right) show avoidance (top), one-footshock escape (middle), and twofootshock escape (bottom) responses. Arrows indicate lever responses, lightning bolts indicate footshocks, trumpets indicate safety periods, levers + lights indicate warning signals. Left, Voltammetric current (z-axis) plotted against applied scan potential (Eapp; yaxis) and time (x-axis). Right, Dopamine concentration traces plotted as a function of time. Inset shows cyclic voltammogram for dopamine. (B) Warning signal presentation increases dopamine release when rats successfully avoid footshock. Mean $(n=9) \pm$ SEM traces depict the time course of changes in subsecond dopamine release as animals minimize punishment by avoiding footshock. Dashed lines represent warning stimulus onset, around which mean data are grouped. Color representations: light gray, maximum warning stimulus duration; dark gray, safety period. (C) Warning signal presentation inhibits dopamine release when rats fail to avoid or escape footshock. Only one-footshock escape trials are included in the mean $(n=9)$. (D) Maximal dopamine concentration evoked by warning signal presentation predicts successful punishment avoidance. 
A

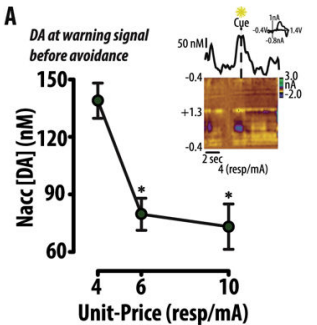

B

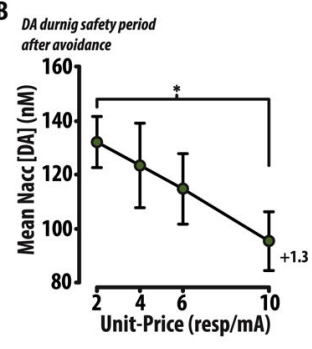

C Increasing DA at warning signal (cue) makes
demand to avoid MORE sensitiviv to price

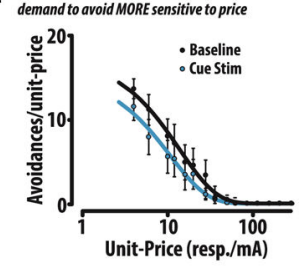

D Increasing DA at succesful avoidance makes

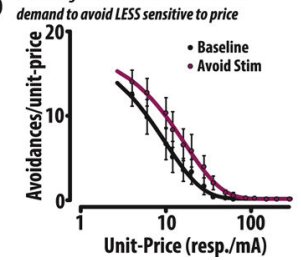

Fig. 5.

Republished from Pultorak et al., 2018 with permission. (A) As animals acquired responding in the economic avoidance task, a suppression of consumptions at the lowest unit-price (2 resp/mA) developed over the course of training. This may represent a conditioned suppression induced by a session onset that predicts an aversive session terminus (15-20 consecutive foot-shocks). (B). Dopamine concentration was concurrently suppressed with behavior at session onset. (C). Optically stimulating dopamine neurons at successful avoidance rectified the suppression of behavior at session onset. 

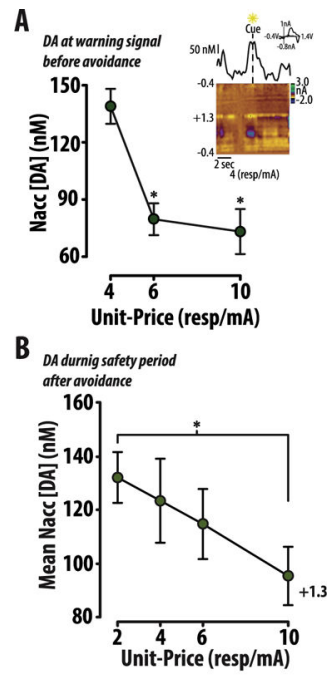

C Increasing DA at warning signal (cue) makes
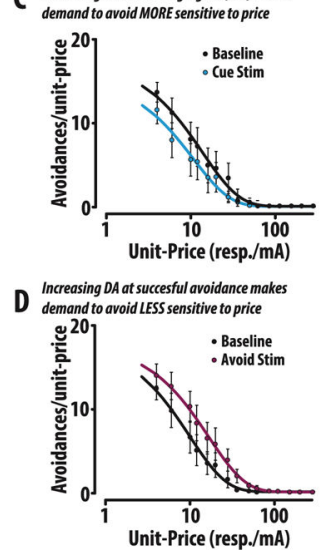

Fig. 6.

(A) The concentration of dopamine evoked by a warning signal that predicted the opportunity to avoid decreased with the price to avoid. (inset). Representative avoidance trial shows that dopamine concentration began increasing in anticipation of warning signal presentation, as the safety period occurred in fixed $30 \mathrm{~s}$ intervals. (B) The concentration of dopamine release events during the safety period decrease with price. $(C, D)$ Optogenetic activation of VTA dopamine neurons at the warning signal made animals more sensitive to price, consistent with a negative reward prediction error. In contrast, optically stimulating dopamine neurons at successful avoidance made animals less sensitive to price, consistent with a positive reward prediction error. 